\title{
Branch apices, heterochrony, and inflorescence morphology in some mimosoid legumes (Leguminosae: Mimosoideae)
}

\author{
James Grimes
}

\begin{abstract}
Grimes, James (Harding Laboratory, New York Botanical Garden, Bronx, NY 10458 USA) 1996. Branch apices, heterochrony and inflorescence morphology in some mimosoid legumes (Leguminosae: Mimosoideae). Telopea 6(4): 729-748. Six species of mimosoid legumes, Paraserianthes lophantha, Zapoteca tetragona, Lysiloma microphyllum, Acacia nilotica, Ebenopsis ebano, and Pithecellobium dulce, are subjects of a study of morphology of inflorescences, branch-apices, and terminal and axillary buds. Differences in patterns of growth in the species can be attributed to shoot-dimorphism, phyllotaxy, and heterochronic differences in development of stipules and unit-inflorescences. Species form only long-shoots or one of two kinds of short-shoots. One kind of short-shoot is formed in a series from an axillary meristem, and is ephemeral if it produces inflorescences. The other is solitary and long-persistent. Inflorescences were found to be produced either on the long-shoots or the short-shoots, but not on both. All inflorescences can be described as pseudoracemes of unit-inflorescences, but differ depending on whether the unit-inflorescences arise from long-shoots or short-shoots, and on whether there is heterochronic development of unit-inflorescences and subtending leaves. The unit-inflorescences develop from primary buds or from secondary buds. Phyllotaxy is either spiral or distichous. Stipules arise either on the flanks of the leaf-primordium, or from primordia spatially independent, but concomitant with the leaf-primordium.
\end{abstract}

\section{Introduction}

An earlier study (Grimes, 1992) of the inflorescence morphology of a group of mimosoid legumes informally called the Pithecellobium-complex (Leguminosae: Mimosoideae: Ingeae) showed that inflorescence morphology is determined not only by the relative arrangement of organs, but also by heterochronic changes in their development. It was also shown that inflorescence morphology is a reflection of the branch morphology, and ultimately of the plant architecture. Most of the differences found in inflorescence- and branch-morphology were attributed to branch dimorphism and to heterochronic differences in timing of development of the leaf-primordia and axillary buds. A subsequent paper (Grimes 1995) presented a phylogenetic analysis of tribe Ingeae (including representatives of Acacieae). The data set for the analysis included a number of characters, or hypotheses of homology, reflecting some of these morphological and heterochronic differences in inflorescences. This paper continues the study of inflorescence morphology in Ingeae, with particular reference to timing of development of the component organs and the formation and development of axillary buds. Specifically, is there a generalized pattern of development such that differences in inflorescence and branch morphology might be attributed mostly to heterochronic phenomena, or are these differences due in part to differences in pathways of development?

Implicit in my approach is the view that if developmental pathways are shared between two species, the developmental pathway is a character (De Queiroz 1985), that modifications of these pathways can be seen as states of the character, and that 'character' and 'character-state' are hierarchy-dependent. That is to say a character at 
one level might be a character-state at another, and that states of a character can arise from modifications of an existing pathway. For example, in a study of the differences in tendril morphology in Pisum, 'tendril' is the character and 'types of tendrils' the states. At a higher level, however, tendril can be seen as a state of the character 'derivatives of a leaf-primordium'. One role of developmental studies then is to determine what, if any, are the differences in developmental pathways, and when (at what stage) they occur. These modifications can be morphological or heterochronic.

In order to facilitate temporal and morphological comparisons, the concept of Repeating Growth Unit (RGU) was introduced as a morphological unit intermediate between metamer and module (Grimes 1992). The RGU is defined as the smallest complete repeating or unitary sequence of metamers produced by a meristem. A module is the series or sequence of RGUs produced by a single apical meristem. An RGU is the same as the module in those cases where an indefinite series of metamers are produced which are morphologically and physiologically indistinguishable. The inflorescence was defined (Grimes, 1992) as that sequence of metamers of a RGU that participates in the production and/or presentation of flowers and fruit.

Briggs and Johnson (1979) introduced terminology dealing with duration of meristems which is followed here. Anthotelic meristems are those that terminate with the formation of a flower. Blastotelic inflorescences do not terminate with a flower and are divided into two types. Auxotelic axes continue growth beyond the flowering region, while anauxotelic ones end in an aborted vegetative apex.

Defined in the context of Repeating Growth Units (Grimes 1992), shoot dimorphism means that different shoots on the same individual are composed of different metamers or sequences of metamers. In architectural terminology shoot-dimorphism is a result of division of meristem labor (Hallé et al. 1978; Tomlinson 1978; Tourn et al. 1992).

Romberger (1963) defined a bud as an unextended, partly developed shoot having at its summit the apical meristem which produced it. Hallé et al. (1978, p. 35) distinguish a rosette from a bud: a bud is enclosed by bud-scales, a rosette by reduced foliage leaves. For descriptive purposes in this paper branch-bud and apical bud both are used to refer to the nodes and associated leaf-primordia that are congested distal to the first elongated internode, regardless of whether covered by bud-scales or foliage leaves.

A primary bud is the first to develop in a leaf-axil (Cremer 1978); accessory buds develop subsequently. Hallé et al. (1978) differentiate between primary and secondary bud complexes. In primary complexes several meristems are initiated separately within a single leaf-axil, most commonly in a transverse or vertical series. Secondary complexes are essentially condensed shoot-systems that apparently result from the branching of an original solitary lateral meristem.

Preformed buds (Brown \& Sommer 1992; cf. Tomlinson \& Gill 1973) are those in which the metamers of a morphogenetic unit (which is more or less equivalent to RGU) are formed but then undergo some period of dormancy in a condensed state. Neoformed buds (Brown \& Sommer 1992) are those in which metamers form and develop with no period of dormancy.

The plastochron is the time between the initiation of one leaf-primordium and the initiation of the next (Mauseth 1988). For descriptive purposes nodes and leaf-primordia are numbered basipetally starting with the one differentiating at the apex (first plastochron, first leaf-primordium).

Heterochrony is the change in relative time of appearance and/or rate of development for characters already present in the ancestor (Gould 1977). So, determining that there has been a heterochronic change and the polarity of the change requires some 
phylogenetic hypothesis. Homeosis is the assumption by one part [of an organism] of likeness to another part', or 'the complete or partial replacement of one structure with a different structure.' Heterotopy is the change in the position of inception of organs (Sattler 1978). Several authors argue that homeosis is a special case of heterochrony (Coen 1991; Hill \& Lord 1989; Lord 1991; Lyndon 1994), and Lyndon (1994) points out that while homeotic genes are often assumed to be positional genes, their role in regulating timing (heterochrony) should be distinguished from any role in affecting position. The role of heterochrony in affecting or effecting heterotopic changes remains unstudied, and the relationships between heterochrony, heterotopy and homeosis require theoretical discussion.

Martinez (1975) published a study of axillary buds but did not include developmental studies. She included two species of Ingeae, Inga uruguensis Hook. \& Arn. and Pithecellobium grisebachianum (= Chloroleucon foliolosum (Benth.) G. P. Lewis), and two species of Acacieae, Acacia caven (Mol.) Mol. and A. visco Lor. ex Griseb. In that paper three types of axillary bud-systems were found: solitary, multiple serial, and multiple biserial. Multiple serial buds are aligned in one series along the axis of the stem; multiple biserial buds occur in a zig-zag or alternate fashion in two series along the axis of the stem. Martinez noted that in all cases maturation of the buds was basipetal, but did not note any differences in timing of maturation of the buds relative to other organ-systems. Individual taxa included in this work will be discussed further and comparisons made below. Chloroleucon foliolosum is quite different in that the buds are apparently preformed and enclosed in perules. Origin of unit-inflorescences and heterochronic differences in formation of leaves and unit-inflorescences were not mentioned. Branch and inflorescence development in the two species of Acacia is apparently quite similar to Acacia nilotica, discussed below. The condition in Inga uruguensis is similar to many discussed herein but, without notes on heterochronic phenomena and developmental studies, more specific comparisons are not possible.

\section{Materials and methods}

The taxa chosen for study were those for which living material was available either from nurseries, or in cultivation by the author or at the New York Botanical Garden. The taxa studied are: Paraserianthes lophantha (Willd.) I. Nielsen, Zapoteca tetragona (Willd.) H. Hern., Lysiloma microphyllum Benth., Acacia nilotica (L.) Willd., Ebenopsis ebano (Berlandier) Barneby \& Grimes, ined., and Pithecellobium dulce (Roxb.) Benth.

Buds were dissected fresh and fixed (or fixed and then dissected) for 24-48 hours in FPA (formalin:proprionic acid:95\% EtOH:water, 5:5:45:45) and stored in 95\% EtOH. Dissection was done on a Wild M5 dissecting scope. Specimens were taken through a dehydration series to $100 \%$ acetone, critical point dried on a Denton DCP-1 apparatus, coated in a Hummer sputter coater with gold-palladium, and examined at 2 or $5 \mathrm{kv}$ on a JEOL JSM-T300 scanning electron microscope.

\section{Results}

\section{Paraserianthes lophantha (Willd.) I. Nielsen (Figs 1, 2a-d, 3a)}

Paraserianthes lophantha is native to the East Indies and south-western Australia. The typical subspecies is widely cultivated, and naturalized in the San Francisco Bay area of California. Observations were made one time on a population in San Francisco, and on plants grown from seed from that population cultivated over two years. 
The species exhibits a generalized pattern of development of monomorphic shoots with a $2 / 5$ phyllotaxy in a counterclockwise spiral on which leaves and inflorescences develop coevally. Growth is anauxotelic and death of the apical meristem in wild populations is apparently seasonal. The apical meristems of plants in cultivation die sporadically, independent of season. The RGU (Fig. 1) consists of a number (in cultivation 6-15 or more) of sterile metamers followed by a number of fertile ones in which 1-4 axillary unit-inflorescences develop sequentially; at anthesis the inflorescence is a pseudoraceme of spikes. The plants exhibit late-suppressed hysteranthy (Grimes 1992). That is, the first-formed inflorescences are subtended by leaves, but the leaves subtending the inflorescences formed toward the end of the RGU are suppressed.

The leaf-primordium forms alone on the apex (Fig. 2a), the stipules being produced on its flank during the second plastochron (Fig. 2b). The leaf-primordium grows very rapidly and by the fourth plastochron the apical bud is protected by a series of enlarged petiole-bases (Fig. 2c): that of the fourth leaf making up nearly $1 / 2$ of the circumference of the bud. Internode elongation starts between the fifth and sixth, or sixth and seventh plastochron. All metamers produce axillary buds in a biserial arrangement, and there is a temporal differentiation of the buds: those at the first-formed nodes of the RGU are vegetative, those at the later formed ones reproductive. In all cases the first bud to develop is sinistral to the mid-line of the leaf (Fig. 2c), and is first visible at the fourth (sometimes fifth) plastochron. Subsequently one or more buds might form in a biserial arrangement, and differentiation is basipetal. The buds resemble those of Lysiloma latisiliquum (see below, Fig. 5b) and are made up of a reduced bract-like structure lateral to the bud-meristem. At older nodes of the RGU the first buds can develop sylleptically as a branch, but most of them remain dormant (Fig. $2 \mathrm{~d}$ ) and very poorly differentiated. Most branching is from proleptically developing buds. Toward the end of the formation of the RGU all buds form spicate unit-inflorescences. The sinistral first-formed bud differentiates before the second-formed one. The bud-meristem itself seems to develop into the unit-inflorescence (Fig. 3a) with no formation of vegetative metamers (cf. Lysiloma microphyllum, below).

\section{Zapoteca tetragona (Willd.) H. Hern. (Figs 1, 3b,c)}

Zapoteca tetragona is widespread from central Mexico south along the Andean Cordillera from Venezuela to southern Ecuador. It is frequently cultivated. Observations were made over the course of two years on several specimens cultivated at the New York Botanical Garden.

In most respects the pattern of growth resembles that of Paraserianthes lophantha. Differences are noted following. Shoots are monomorphic and in cultivation at least auxotelic (Fig. 1). The RGU consists of a series of $\pm 3-9$ sterile metamers consisting of leaves, stipules, and axillary buds, and $\pm 3-$ ? reproductive ones in which some of the axillary buds develop sylleptically into unit-inflorescences. There is no apparent modification of a resting bud, and while the plants grew faster during some times of the year than others, no period of real dormancy was noted. In contrast to $P$. lophantha, phyllotaxy is distichous at inception (Fig. 3b), though on plagiotropic shoots the leaves are displaced somewhat toward the upper side, so that the angle between them is about $160^{\circ}$. The stipules develop on the apex with, or even slightly before, the leaf-primordium, and by the second or third plastochron become much larger than the associated leaf-primordium. The growing buds, though enclosed in a envelope of precociously developed stipules, are not, as mistakenly stated by Grimes (1995, in data set), preformed. Axillary buds start to develop during plastochron four or five, and form an obconical bud lacking bracts or scales (Fig. 3c). The first bud is sinistral, subsequent buds form in a multiple biserial series as in 


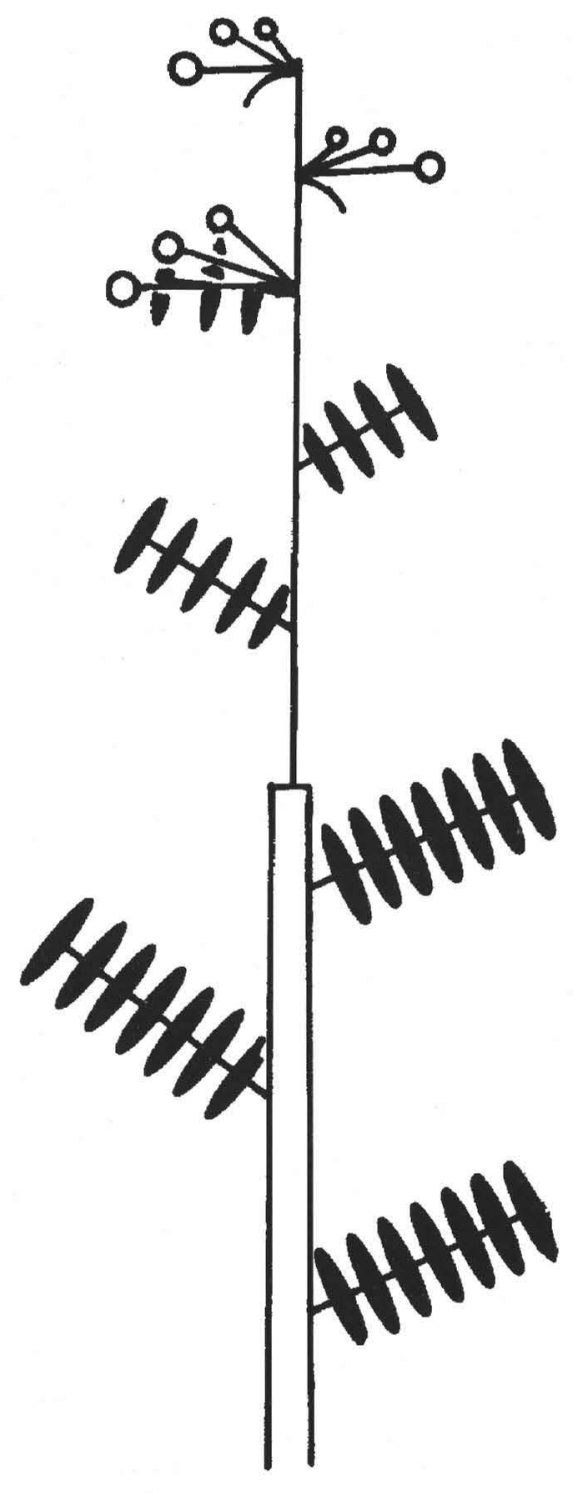

-- bract
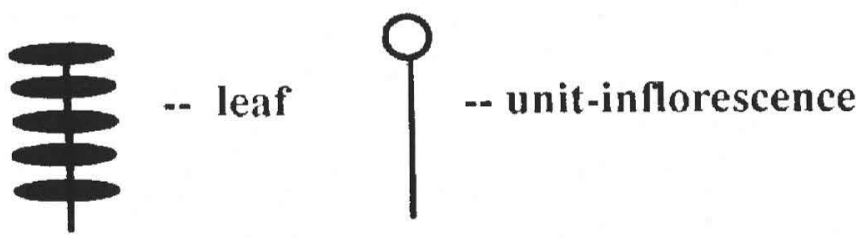

Fig. 1. A diagrammatic representation of the growth of Paraserianthes lophantha and Zapoteca tetragona. Hollow stems represent the last RGU (see text), solid stems the current RGU. In both species the RGU is made up of a series of sterile metamers followed by a series of fertile ones. The species exhibit late-suppressed hysteranthy, in which the leaves subtending the first-formed unit-inflorescences are developed, but those subtending the later ones are suppressed. 
Paraserianthes lophantha. Elongation of the internodes takes place during plastochron seven or eight. In the specimens in cultivation branching was proleptic, and occurred only after the terminal bud had been excised. Inflorescences did not form on the specimens in cultivation, but on herbarium specimens are pseudoracemes of capitula similar in form to the inflorescence of Paraserianthes lophantha.

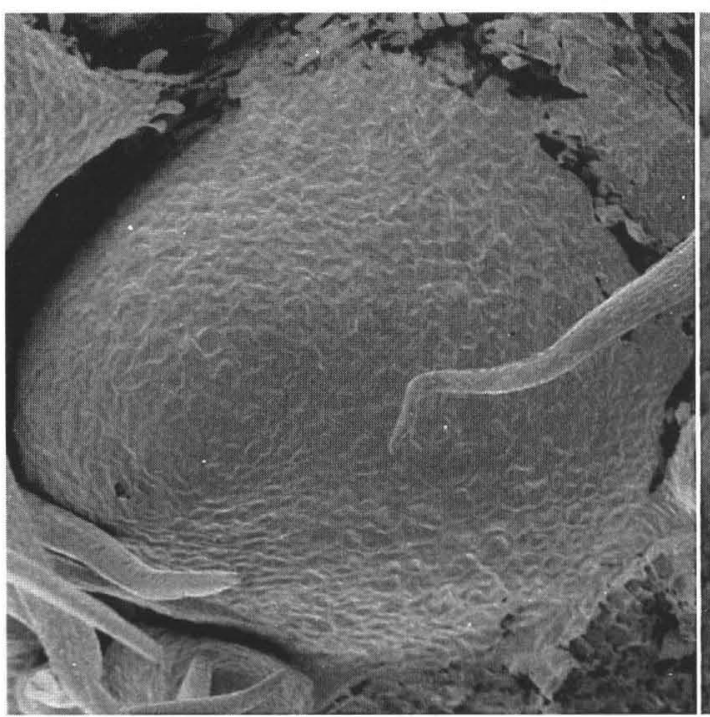

a

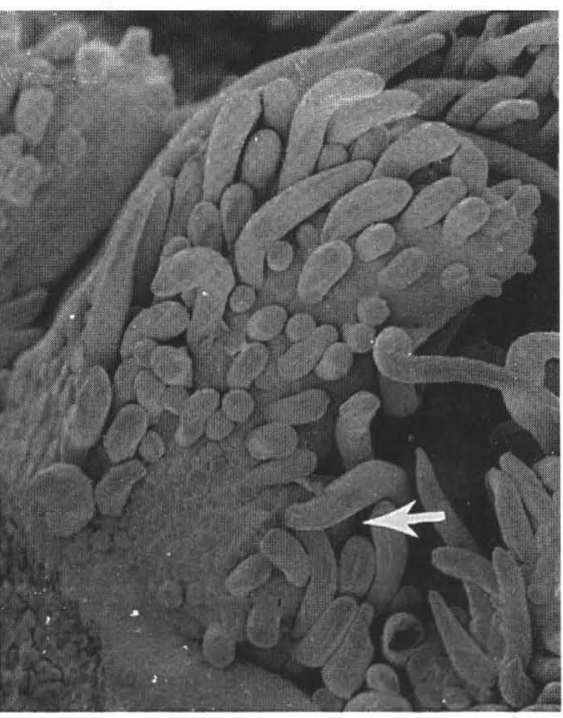

b

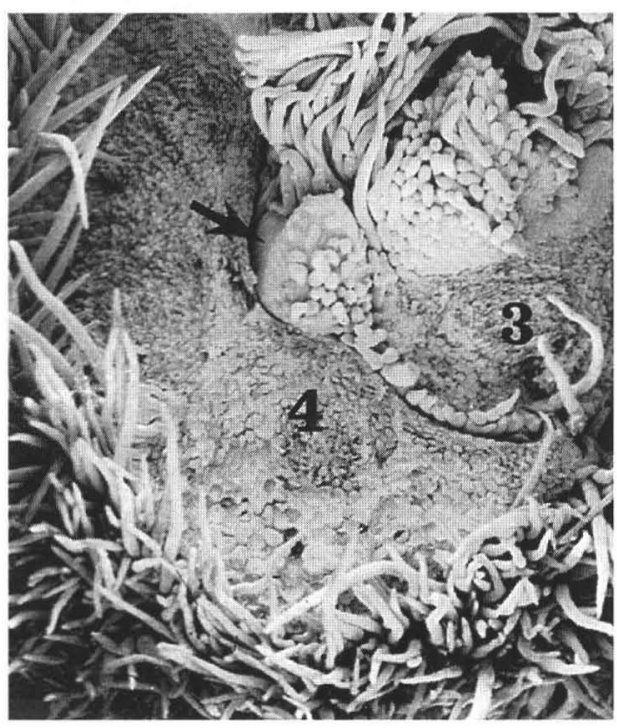

C

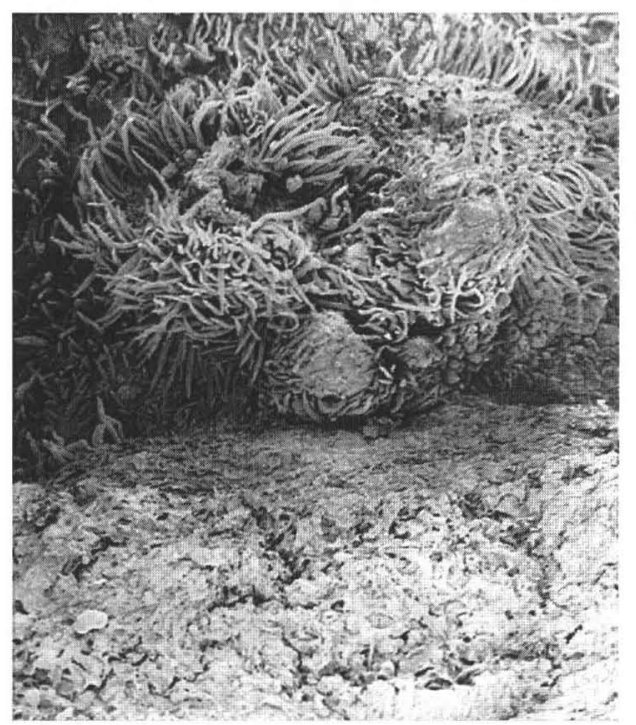

d

Fig. 2. Scanning electron micrographs of Paraserianthes lophantha. a, apical meristem $(\times 350)$, the leaf-primordium is visible as a bump at 9 o'clock; b, the leaf one plastochron later, the arrow shows the differentiating stipules $(\times 200)$ partly hidden by a trichome; $\mathbf{c}$, apical region $(\times 100)$. The numbers 3 and 4 show where the third and fourth leaves were removed, the petiole of the fourth leaf encircled nearly half of the circumference of the bud. The arrow shows the axillary bud, which has developed in the leaf-axil between the third and fourth plastochron; d, dormant axillary buds at an old node. 
Lysiloma microphyllum Bentham (Figs 3d, 4, 5a-d)

Lysiloma microphyllum is widespread in Mexico from the Cordillera Occidental of Sonora south to Oaxaca, east into San Luis Potosí and Puebla. Observations were made on one mature (reproductive) and one juvenile plant in the conservatory of the New York Botanical Garden. Morphology of the stems, and growth and flowering are quite complicated and more long-term observations on wild populations are needed.

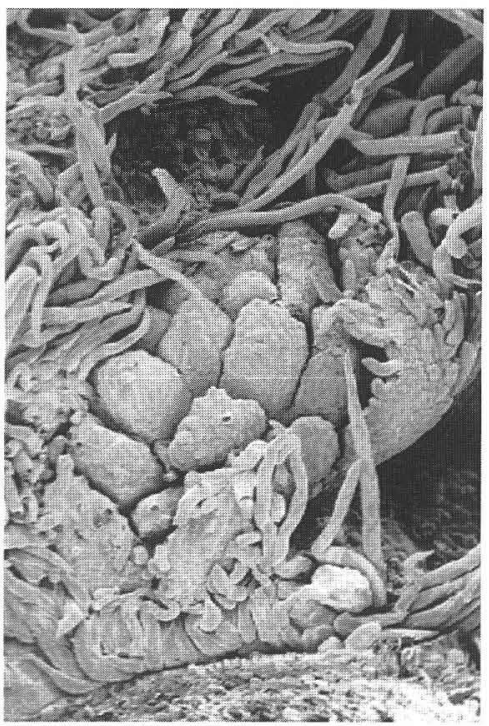

a

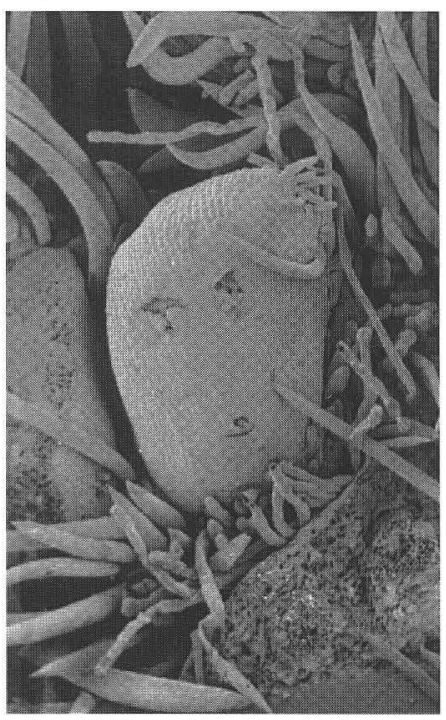

C

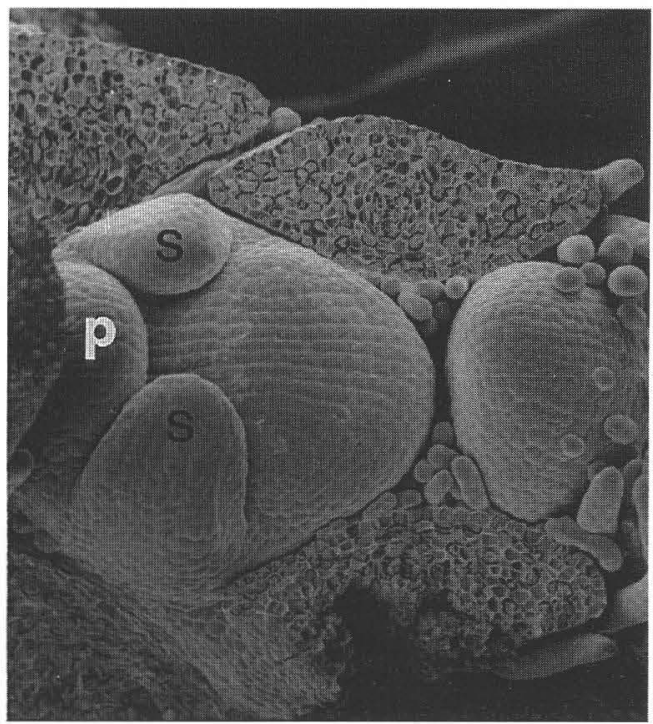

b

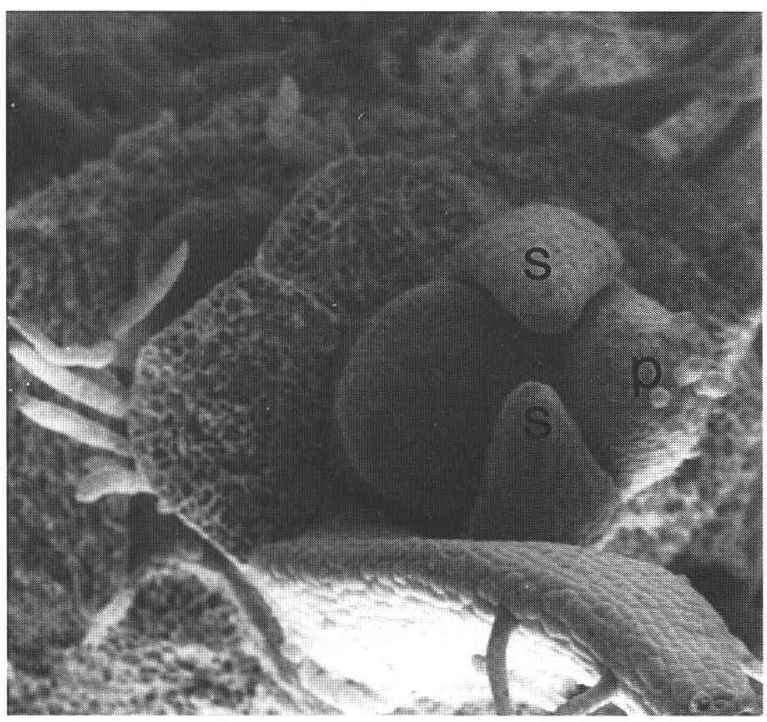

d

Fig. 3. Scanning electron micrograph of three species of Ingeae. a, developing unit-inflorescence of Paraserianthes lophantha $(\times 100)$. The bract to the right is part os the same bud forming the unit-inflorescence; $\mathbf{b}$, stem-apex of Zapoteca tetragona $(\times 200)$; $\mathbf{c}$, axillary bud of $Z$. tetragona seven plastochrons after initiation of associated leaf-primordium $(\times 75)$; d, stem-apex of Lysiloma microphyllum $(\times 200)$. In this and subsequent micrographs $\mathrm{b}=$ bract, $\mathrm{s}=$ stipule $\mathrm{p}=$ leaf-primordium. 
The species has anauxotelic dimorphic shoots (Fig. 4), and RGUs on both long-shoots and short-shoots are delimited by a period of dormancy with no morphological differentiation of the dormant branch-apex other than the withered remains of the aborted bud. The RGU of long-shoots consists of $\pm 3-7$ metamers consisting of a primary leaf and associated stipules, and usually a pair (sometimes more) of axillary buds with perules. At the apex, the leaf-primordium and stipule-primordia arise separately (Fig. 5a). The stipules develop precociously relative to the leaf, and reach nearly adult size even before internode elongation. This latter takes place sometime after the fifth (usually after the sixth) plastochron. The terminal bud is enclosed in a series of these enlarged stipule-pairs, but the bud is not preformed. Axillary buds develop between the fifth and sixth plastochron, and apparently form in a serial file (Fig. 5c), though a third bud has not been observed to form. At most nodes buds remain dormant and the base of the petiole grows up around the bud-complex, sometimes nearly enclosing them (Fig. 5c). Branching is proleptic, apparently at nodes that have previously flowered. Axillary buds are of two different types. Newly formed vegetative buds are similar in morphology to those of Paraserianthes lophantha in that they consist of bract and apical region (Fig. 5b), though curiously, old ones are obconical and resemble those of Zapoteca tetragona. After starting to develop the bud has an apex similar to that of the long-shoot apex, with distichous phyllotaxy. Likewise, though the stipules arise concomitant with the leaf-primordium, they develop much more quickly (Fig. 5d). The second type of bud is apparently reproductive, and its development differs from both that of the long-shoot and that of vegetative short-shoots in that phyllotaxy is apparently spiral, though this interpretation needs confirmation. Furthermore the stipules do not develop to any appreciable extent. Unlike the bud in Paraserianthes lophantha, the short-shoot in L. microphyllum grows at the apex, producing a series of reduced leaves, and the unit-inflorescences arise axillary to these (Fig. 6a). Fig. 6a shows an inflorescence arising on a sylleptically developing short-shoot. In either case most inflorescences develop precociously relative to the subtending leaf.

Flowering is independent of long-shoot development, and many short-shoots bloom proleptically after the long-shoot has finished formation. Sometimes, though, unit-inflorescences develop both on short-shoots and seemingly on long-shoots, though in the latter on very reduced short-shoots. When in flower the inflorescence on some specimens resembles the pseudoraceme of capitula seen in Paraserianthes lophantha and Zapoteca tetragona (cf. Figs 1 and 4), but in reality they are different. The unit-inflorescences in the latter two species develop directly from primary buds concomitant with the RGU on which they form (i.e. sylleptically). In contrast, while the inflorescence of L. latisiliquum may be described as a pseudoraceme of capitula in that there are unit-inflorescences distributed along a long-shoot, the species exhibits shoot-dimorphism: one type of RGU is the long-shoot that develops from the apical meristem, and a second type of RGU is the reproductive or vegetative short-shoot that develops proleptically. Following the definition of inflorescence of Grimes (1992) then, the disposition of flowers along the long-shoot is not the inflorescence and L. latisiliquum has two kinds of inflorescences: those developing sylleptically on short-shoots that are subunits of an RGU, and those developing proleptically on short-shoots that are themselves RGUs.

\section{Acacia nilotica Bentham (Figs 4, 6b,c)}

Acacia nilotica is a member of subgenus Acacia, and is widespread in tropical Africa, through southern Asia into the Indian subcontinent. Observations were made on two plants cultivated by the author. As neither has bloomed, phenology has been inferred from herbarium specimens. 
Though the growth form superficially resembles that of Ebenopsis ebano (following) in that the species possesses stipular spines and axillary short-shoots, in growth pattern A. nilotica is more similar to Lysiloma microphyllum (Fig. 4): flowering occurs only on short-shoots, and these can develop sylleptically or proleptically. The RGU of the long-shoot is of a series of metamers, which are produced indefinitely in the greenhouse

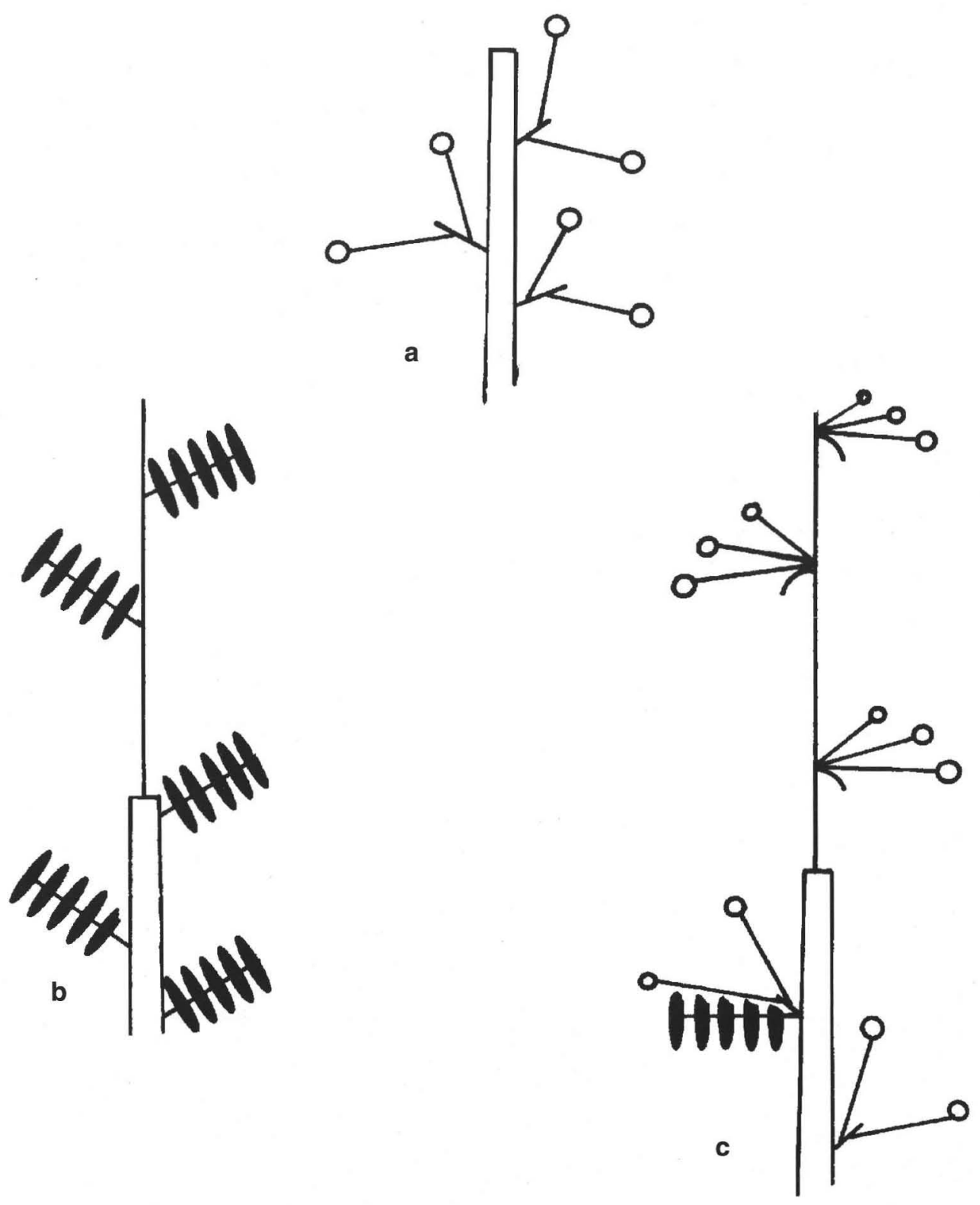

Fig. 4. Diagrammatic representation of the growth of Lysiloma microphyllum and Acacia nilotica. $a$, the repeating growth unit of non-blooming long-shoots; b \& c, short-shoots. All flowers are produced on short-shoots. b, flowering from proleptically developing short-shoots only, independent of any long-shoots expansion; c, flowering on both proleptically and sylleptically developing short-shoots, the proleptic ones on the penultimate RGU. 
as long as water is provided. When drought-stressed, as is undoubtedly the wild condition, the apical meristem dies: growth resumes from an axillary bud near the apex. Phyllotaxy is spiral and counterclockwise, and the metamers consist of the leaf, associated stipular spines, and axillary buds. The stipules do not arise on the apex with the leaf-primordium, but rather develop late in the second plastochron or between the second and third (Fig. 6b) on the flanks of the leaf-primordium proper. Subsequent growth is rapid, and the apical bud is more or less protected by the numerous spines.

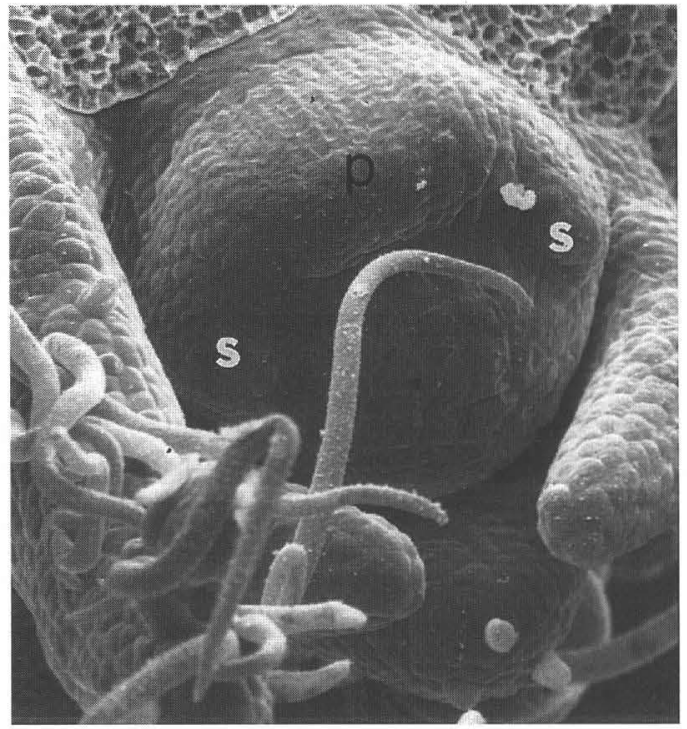

a

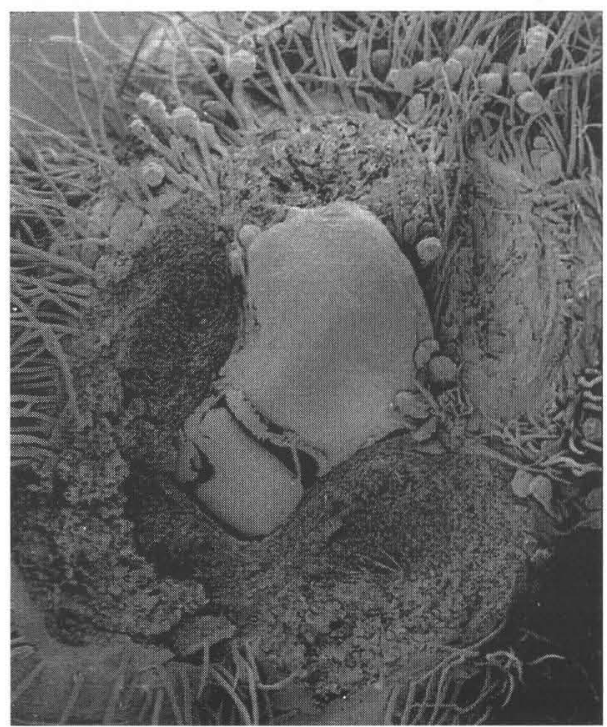

C

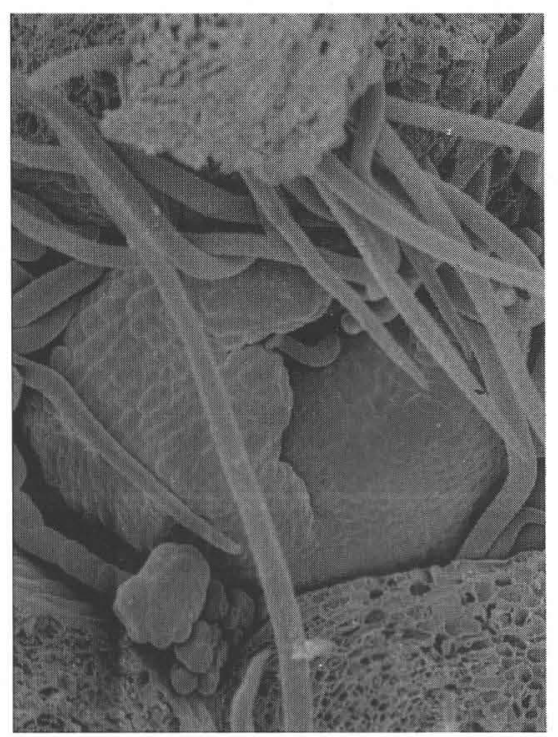

b

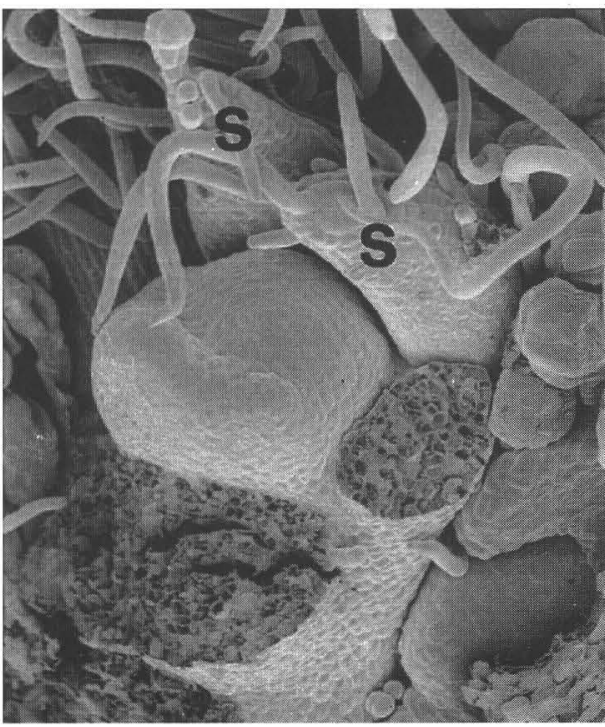

d

Fig. 5. Scanning electron micrographs of Lysiloma microphyllum. a, apex of long-shoot $(\times 350)$; b, axillary bud $(\times 200)$; c, two axillary buds in a vertical series, the oldest bud distal to the youngest $(\times 35)$; $d$, apex of an axillary bud. 
Axillary buds are multiple biserial (Fig. 6c). These buds are produced sequentially over many years; commonly one will change into a long-shoot. As in Lysiloma microphyllum flowering occurs strictly on short-shoots, which develop sylleptically or proleptically. The development of the unit-inflorescences is precocious relative to the subtending leaf and is apparently similar to that of Acacia caven and A. visco, reported by Martinez (1975).

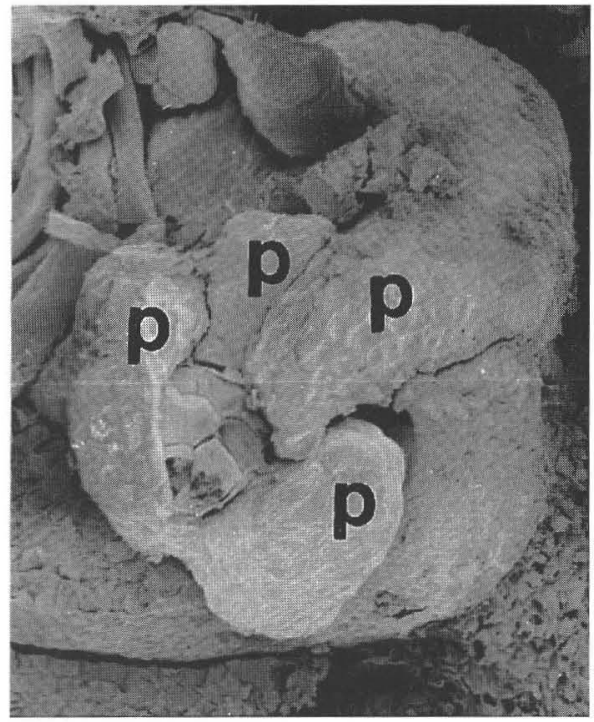

a

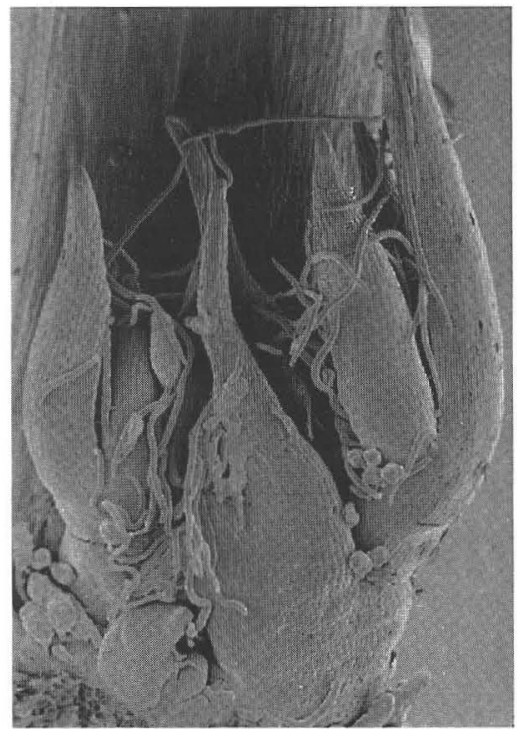

C

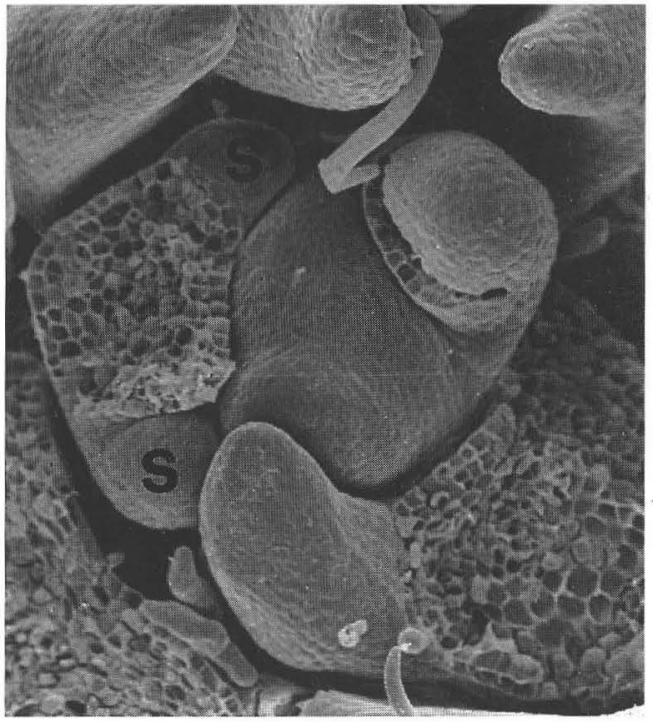

b

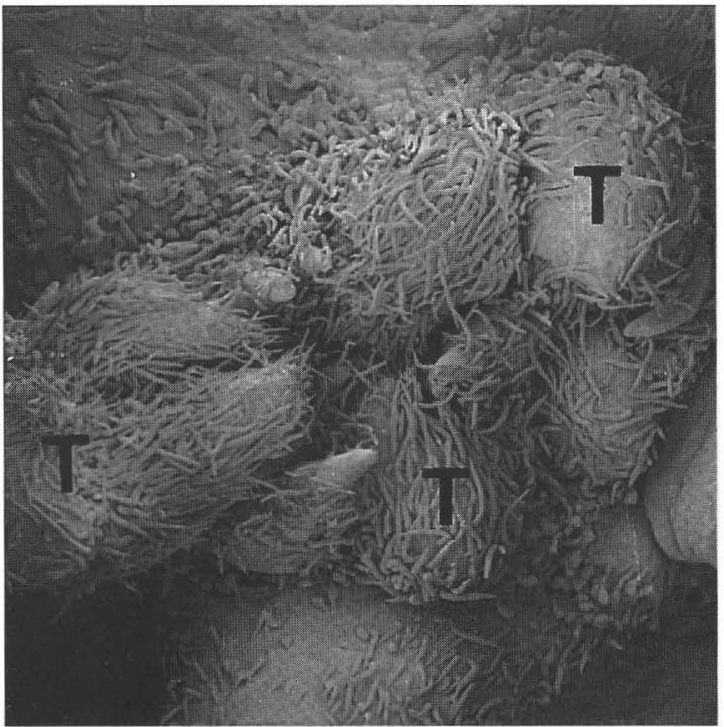

d

Fig. 6. Scanning electron micrographs of several species of Ingeae. a, axillary bud of Lysiloma microphyllum with developing unit-inflorescence $(\times 350) ; \mathbf{b}, \mathbf{c}$, Acacia nilotica. b, apex of stem $(\times 200)$. Stipules are clearly visible at the third plastochron; c, multiple serial buds $(\times 50)$; d, Ebenopsis ebano, axillary bud $(\times 35)$. The leaf-primordia form an enlarged buttress $(\mathrm{T})$ that partially covers the meristematic region. 


\section{Ebenopsis ebano (Berl.) Barneby \& Grimes (Figs 6d, 7, 8a-d)}

Ebenopsis is a genus of three species confined to the south-western United States and Mexico. The species are all drought-deciduous thorny shrubs with axillary brachyblasts. Ebenopsis ebano is common in thickets and subtropical deciduous woodlands in north-eastern Mexico (also disjunct in Yucatan) and south-eastern Texas. Observations were made on a pair of plants cultivated in the Conservatory of the New York Botanical Garden over the course of five years, and a one-time visit to a population in Live Oak County, Texas.

The species exhibits shoot-dimorphism, with long-shoots and short-shoots (brachyblasts). All shoots are auxotelic. Phyllotaxy is spiral in a counterclockwise direction on both long- and short-shoots (Fig. 8a). The RGU of the long-shoots (Fig. 7) is made up of (most commonly) 1-6 metamers each consisting of a primary leaf, associated stipular spines, and a sylleptically formed axillary bud. RGUs are delimited by a period of dormancy, with no morphological differentiation of the dormant branch-apex. The stipules arise independent of but concomitant with the leaf-primordium (Fig $8 \mathrm{~b}$ ), but develop much more rapidly. The primary leaf persists during the development of several subsequent RGUs, even after the short-shoots themselves start to produce leaves. The first axillary bud is visible usually at the third plastochron but remains dormant through the seventh (Fig. 8c). Internode elongation takes place between the seventh and eighth plastochron, at which time the axillary bud develops into a short-shoot (Fig. 8d).

The RGU of the short-shoot consists of a series of fertile metamers with leaves and axillary unit-inflorescences produced in the same phyllotaxy as the long-shoots, but the stipular spines of the short-shoots develop neither as quickly nor to such an extent as those on the long-shoots. The RGU of the short-shoot differs from that of the long-shoot in that the internodes fail to elongate, and all buds axial to leaf-primordia form unit-inflorescences. The primordia giving rise to the unit-inflorescences develop precociously relative to the subtending leaf, that is there is some delayed or perhaps late-suppressed hysteranthy. The inflorescence is a pseudoraceme of capitula, but there is only one inflorescence per node. Short-shoots uncommonly change into long-shoots, but do so only after several years. Most short-shoots continue to produce nodes for a limited number of years: eventually they are grown over by secondary growth of the stem.

\section{Pithecellobium dulce (Roxb.) Bentham (Figs 9, 10a,b)}

Pithecellobium dulce is native from Mexico through Central America south into Colombia and Venezuela, but cultivated throughout the world. Observations were made over the course of several years on a specimen (since destroyed) cultivated at the Conservatory of the New York Botanical Garden.

Shoots are dimorphic (see below) and growth is apparently anauxotelic, but this needs to be confirmed on wild trees as the specimen cultivated at the New York Botanical Garden was regularly pruned. The RGU (Fig. 9) consists of a series of vegetative metamers (a dozen or so on a healthy branch) consisting of well developed leaves, stipular spines, and axillary buds, followed by a series (up to 20 or more on healthy branches) of reproductive metamers consisting of nodes with suppressed leaves and axillary branches, also with suppressed leaves. Phyllotaxy is spiral (Fig. 10a), though in contrast to Ebenopsis ebano and Acacia nilotica the spiral is clockwise. Stipules do not arise on the apex, but rather from the flanks of the leaf-primordium; they first become visible around the fourth plastochron (Fig. 10a). Axillary buds are first visible at the fifth plastochron (Fig. 10a), and are centric relative to the subtending leaf-primordium. Subsequently, other buds form lateral to the first, and are triserial (Fig. 10c). Internode elongation takes place after the seventh 
or eighth plastochron, and during this time the axillary bud develops into a shortshoot consisting of reduced leaves and suppressed internodes (Fig. 10b).

The buds of the vegetative and reproductive metamers are the same in appearance. Those on the vegetative metamer will uncommonly develop into a long-shoot branch. Pithecellobium dulce exhibits late-suppressed hysteranthy (Grimes 1992), so leaf formation is suppressed (delayed) at all nodes forming unit-inflorescences. Unit-inflorescences develop in the axils of the leaf-primordia which make up the bud-complex, with two to several unit-inflorescences developing sequentially (not simultaneously) at each node. Often on reproductive metamers one of the buds will develop into a branch, but all the leaves are suppressed, and unit-inflorescences form at each node. These branches usually persist and become leafy, though on the specimen observed they never formed a major branch. Proleptically formed branches follow the same pattern of vegetative and reproductive metamers as the orthotropic branch.

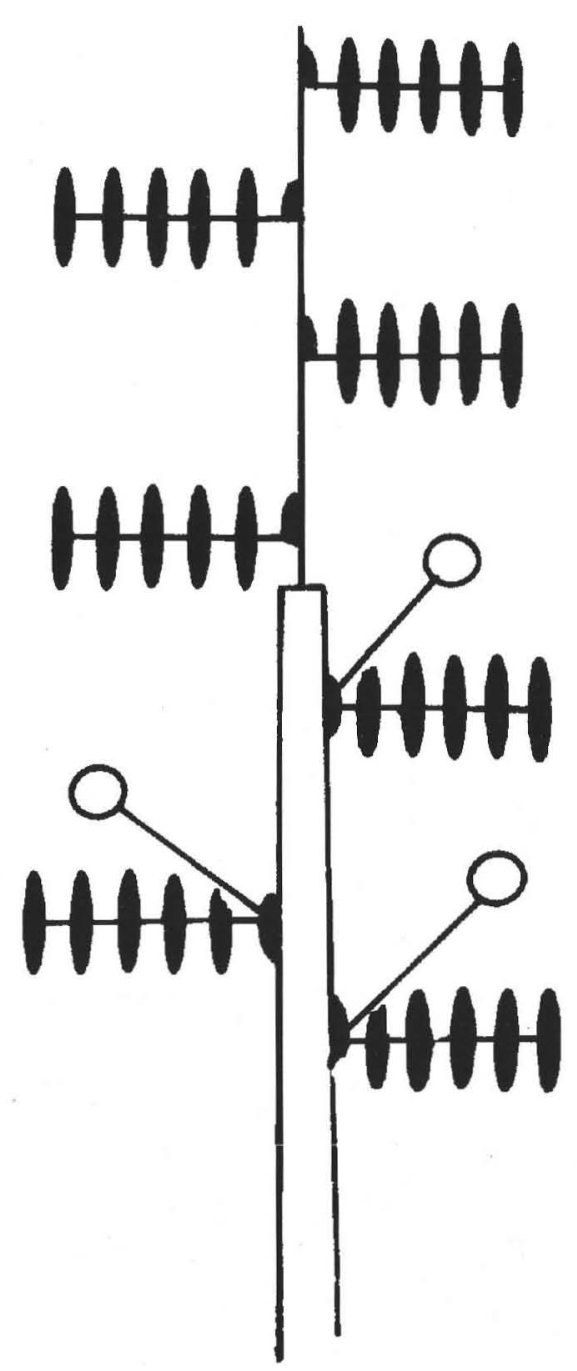

Fig. 7. Diagrammatic representation of the growth of Ebenopsis ebano. The black half-circles represent short-shoots. 


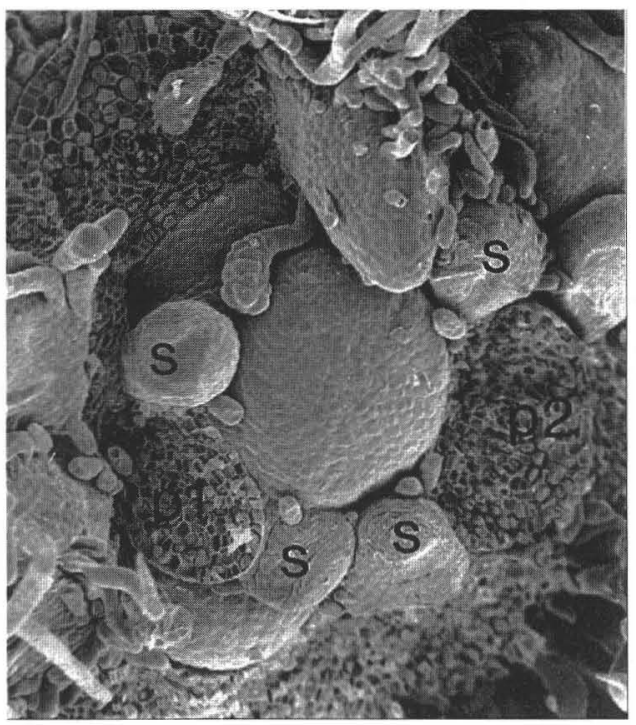

a

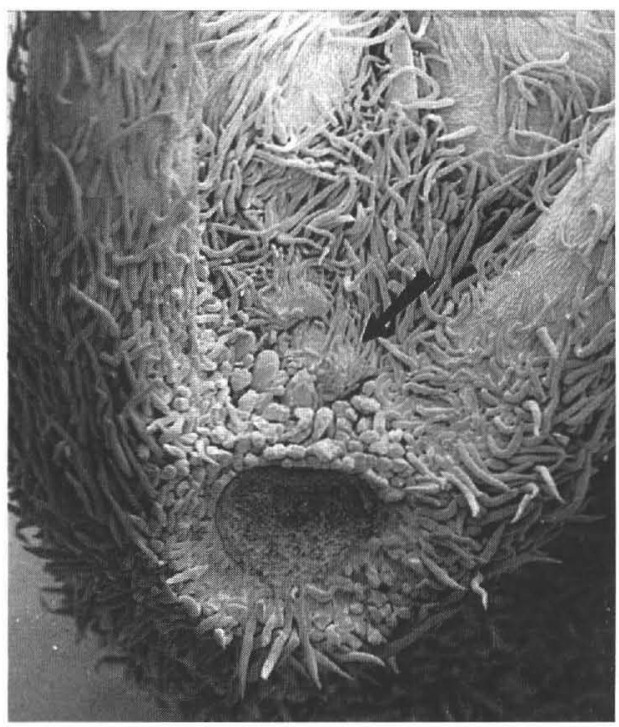

C

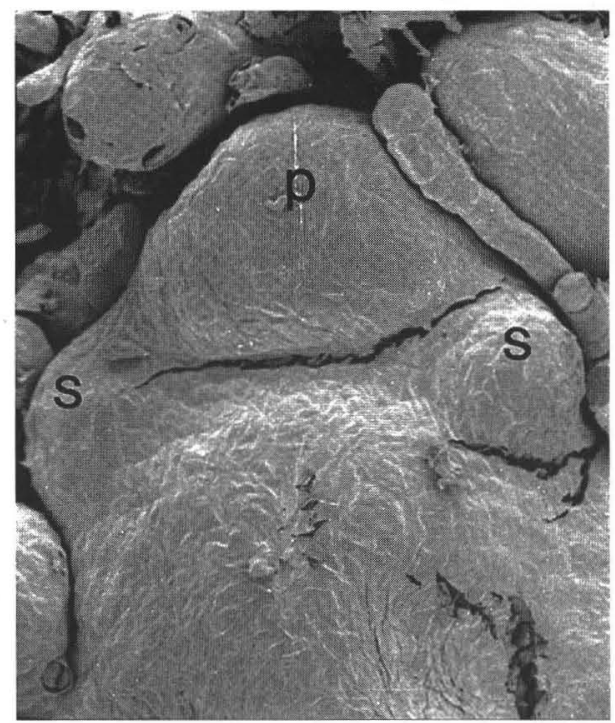

b

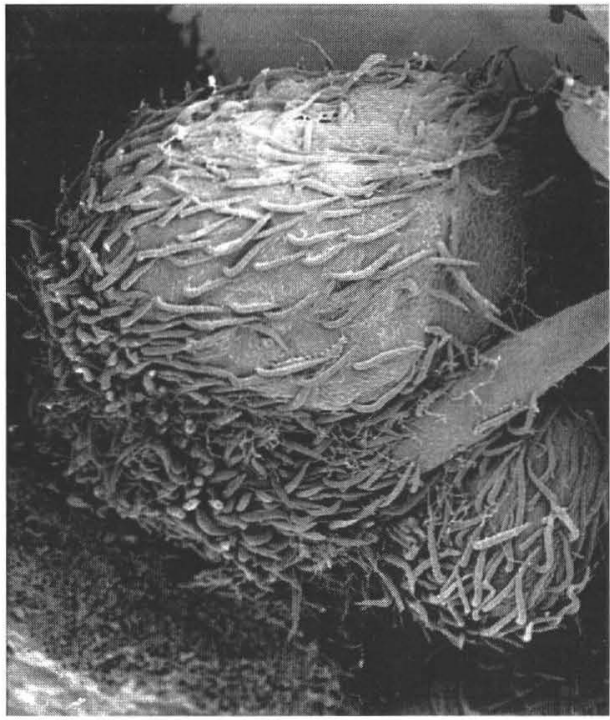

d

Fig. 8. Scanning electron micrographs of Ebenopsis ebano. a, apical region $(\times 200)$; b, apex $(\times 350)$. The crack is an artefact; c, a very reduced axillary bud (arrow) seven plastochrons after initiation of associated leaf-primordium; $\mathbf{d}$, axillary bud eight plastochrons after initiation of associated leaf-primordium $(\times 50)$. 


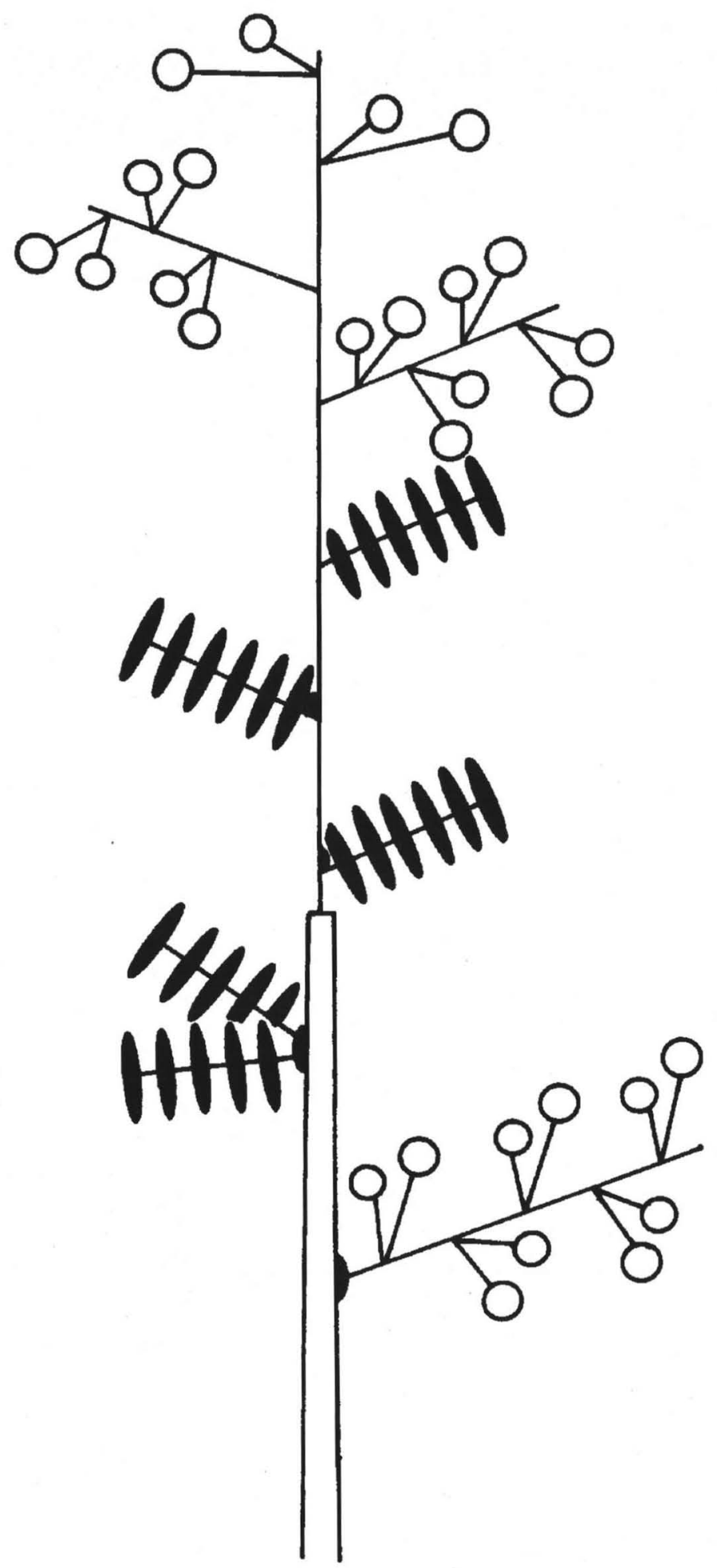

Fig. 9. Diagrammatic representation of growth of Pithecellobium dulce. 


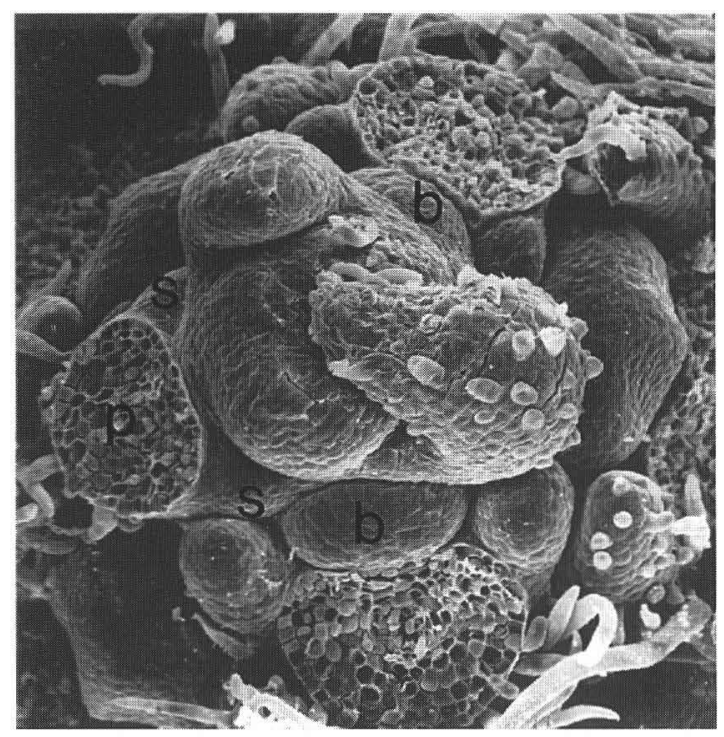

a

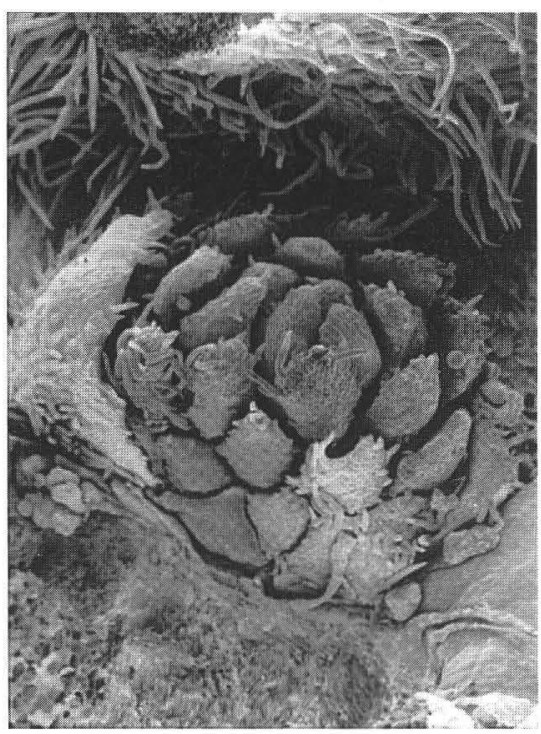

b

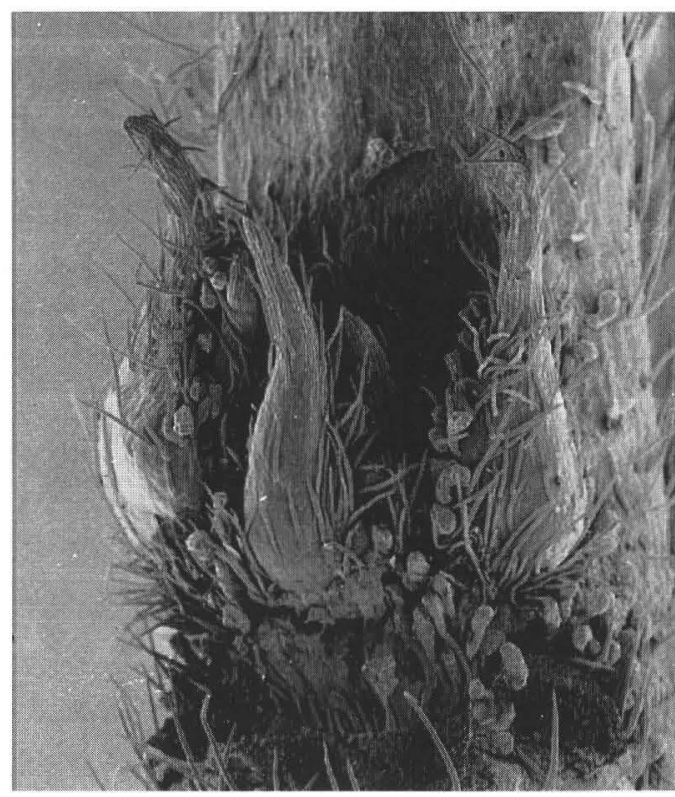

C

Fig. 10. Scanning electron micrographs of Pithecellobium dulce. a, stem-apex $(\times 200)$; b, mature inflorescence-bud $(\times 100)$, the subtending leaf has been removed; c, multiple, triserial buds $(\times 50)$. 


\section{Discussion}

No single generalized pattern of development of shoots and inflorescences has been found for the species examined. All species are alike in that the leaves are neoformed (versus preformed, see Brown \& Sommer 1992), and axillary buds form within the first 8 plastochrons. They are also alike in that there are no morphological differences between sylleptic and proleptic vegetative buds (cf. Tomlinson 1978; Tomlinson \& Gill 1973). Furthermore the axis of most shoots producing unit-inflorescences are persistent. The major differences in the species herein examined can be found in phyllotaxy, morphology of the axillary buds, and in timing of development of stipules and unit-inflorescences.

Zapoteca tetragona and Lysiloma microphyllum both have distichous phyllotaxy, while Ebenopsis ebano, Acacia nilotica, Paraserianthes lophantha and Pithecellobium dulce have 2/5 spiral phyllotaxy. Martinez (1975) also noted distichous phyllotaxy in Inga uruguensis Hook. \& Arn. In E. ebano, A. nilotica, and P. lophantha the spiral is counterclockwise, while in $P$. dulce it is clockwise. Though this is true of all shoots on the individuals examined, it has not been determined if it is true for the species as a whole. Dormer (1954) and Tucker (1963) noted that in the species they studied the phyllotactic pattern alternates between orthotropic and plagiotropic shoots. In most of the species studied here the distinction between orthotropic and plagiotropic shoots is arbitrary, but when two types are distinguishable, the phyllotactic pattern remains the same on both. In Lysiloma microphyllum the phyllotaxy on long-shoots and vegetative short-shoots is distichous, that of reproductive short-shoots is apparently spiral though this interpretation needs confirmation.

Most of the species exhibit a gradual elongation of the internodes, that is elongation takes place more or less continually from the first plastochron. In E. ebano, however, elongation of the internode on long-shoots is abrupt and always takes place between the seventh and eighth plastochrons.

The buds, either axillary or terminal, are protected in one of three ways, these are comparable to the characters used in the cladistic analysis of Ingeae (Grimes 1995). In Paraserianthes lophantha the leaf-rachis enlarges rapidly, and the apical meristem is protected by a series of these enlarged rachises (char. 18, Grimes 1995). In Acacia nilotica and Ebenopsis ebano the apical meristem is protected by stipular spines, even though the two species differ in the time of inception of the stipules (see below). The apical meristem of Ebenopsis is further protected by an enlarged buttress formed by the leaf-rachis. In Zapoteca tetragona and Lysiloma microphyllum the apical meristem is protected by the enlarged, overlapping, foliaceous stipules. L. microphyllum, furthermore, protects the dormant axillary buds by partially surrounding them in the petiole-base. In the data set for cladistic analysis (char. 19, Grimes 1995) the buds of these last two species were interpreted as preformed (sensu Brown \& Sommer 1992). This is incorrect. Though the buds appear preformed, there is either no period of dormancy and the shoots grow throughout the year, or if there is some dormancy, all the metamers that make up the RGU are not already formed within the buds. (Note that this should have no effect as the character can be redefined as: buds 0 - not enclosed by stipule-pairs, 1 - enclosed by stipule pairs). Stein (1975) noted that the stem-apex of Hymenaea courbaril is likewise protected by stipule-pairs that cover their associated leaf. He considered this to be an unusual condition.

There are two different types of axillary bud 'systems' in the species examined that only partially conform to the definition of primary and secondary bud complexes of Hallé et al (1978). Primary complexes, or those in which several meristems are initiated separately within a single leaf-axil, are known in Acacia nilotica, Zapoteca 
tetragona, Paraserianthes lophantha, Lysiloma microphyllum and Pithecellobium dulce; in these cases all are biserial or triserial bud systems, as is common in other legumes (Dormer 1954; Martinez 1975). At any given node axillary buds are produced in a zig-zag fashion by a meristematic region in the axil; maturation is basipetal. The buds are actually short-shoots with two or three nodes. In most of the species these buds remain undeveloped, but in Acacia nilotica most of them develop proleptically as long-shoots. At any given node, the meristematic region in the axil is capable of giving rise to other buds. No matter how many buds are formed, however, the meristematic region remains in the axil. Cremer (1972) calls this an axillary meristem. In contrast, the bud of Ebenopsis ebano develops as a short-shoot with the same phyllotaxy as the long-shoot, but with internodes that do not elongate. In contrast to the serial bud system, no other bud has ever been observed to form at a node in this species. The meristematic region remains at the apex of the shoot in E. ebano, rather than in the leaf-axil as in the other species. This type of bud system is not accommodated in the definitions of Hallé et al. (1978).

Pithecellobium dulce and Paraserianthes lophantha clearly have two kinds of buds: multiple serial buds that evidently produce all vegetative branching, and primary buds that develop directly into inflorescences. In $P$. lophantha these two types are more or less separated: the vegetative ones occur on older metamers of any RGU, the reproductive ones on younger. Zapoteca tetragona is probably much like $P$. lophantha. In $P$. dulce, however, there is evidently some mixing of the two types of buds at some nodes. Lysiloma microphyllum clearly only has one type of bud, which develops into a short-shoot on which inflorescences can form, and from which long-shoots can develop. Likewise Ebenopsis ebano has but one kind of primary bud that develops into a short-shoot.

In Acacia nilotica a leaf will often form on one of the buds with no shoot-elongation, and it then appears that a short-shoot has formed. However, there is no continued development of nodes with suppressed internodes. If the apex does become meristematic, the product is always a long-shoot. The characters used in the cladistic analysis do not adequately reflect these differences (chars. 7 \& 8, Grimes 1995). While the Acacia nilotica -type of short-shoot and the Ebenopsis ebano -type are both branch systems with suppressed internodes, their development is not the same.

There is a difference in time of origin of the stipules in the species examined. In Ebenopsis ebano, Lysiloma microphyllum and Calliandra surinamensis the stipules arise directly on the apex simultaneously with, but apparently independent of, the leaf-primordium. In Acacia nilotica, Paraserianthes lophantha, and Pithecellobium dulce the stipules arise on the flank of the leaf-primordium. Assuming that the stipules in all these species are homologous, this difference is heterochronic: the stipules of E. ebano, L. microphyllum and C. surinamensis arise sooner than in the other three species. They also arise apparently spatially independent of the leaf-primordium directly from the apical meristem; it appears that their placement relative to the leaf-primordium has been changed. In this instance then heterotopy might be a result of a heterochronic change.

Heterotopy has not been studied to the same degree as homeosis. It has been studied in the context of epiphyllous inflorescences (e.g., Dickison 1978; Dickison \& Sattler 1974; Sattler 1975a), roots (Yamashita 1970, 1972), and leaves (Sattler \& Maier 1977). Sattler (1975b) provided a generalized discussion, and later (1978) examined heterotopy in the context of fusion and floral morphology. In none of these works is the relationship between heterotopy and heterochrony mentioned, though the idea that homeosis is a result of heterochronic change is becoming widely accepted (cf. Coen 1991; Hill \& Lord 1989; Lord 1991; Lyndon 1994). As the taxa studied here are widely distributed on the published cladogram (Grimes 1995), little may be said 
about the polarity of the heterotopic change in stipule inception until a better resolved cladogram becomes available, and morphology of the stem-apex of more species is studied. Sattler (1978) pointed out that though the position of an organ may be evident, the direction of change (i.e., polarity) may not be known, and cautioned that one cannot assume that the unusual position is necessarily derived.

All the species studied possess inflorescences which at anthesis can be described as pseudoracemes of capitula, and while the unit-inflorescences are probably homologous, the differences found clearly show that the pseudoracemes of capitula are not homologous as a type of inflorescence. They differ in heterochronic changes, and in hierarchical origin of unit-inflorescences. In Paraserianthes lophantha and Pithecellobium dulce the unit-inflorescence forms directly from the apical meristem of a primary bud (a bud formed directly in the leaf-axil). Though the meristem is covered by a bract, no other bracts form above the inflorescence. In Lysiloma microphyllum, in contrast, the inflorescences clearly form axillary to leaf-primordia (?bracts) on short-shoots; the primary bud itself is a condensed shoot-system and the meristem of the unit-inflorescence forms from a secondary bud. This stage of inflorescence-development has not yet been seen in the other species. Few would disagree that the unit-inflorescences (capitula or spikes) are homologous between the taxa studied here, and indeed probably throughout the subfamily Mimosoideae. However, the variation in position of the unit-inflorescences might better be seen as a separate character of a different order.

The major heterochronic difference in terms of origin of inflorescences can be seen as a temporal difference in the fate of buds. In Ebenopsis ebano all inflorescences arise on short-shoots axillary to a leaf, which develops more slowly. All nodes formed on the short-shoot apparently form unit-inflorescences. In $P$. lophantha, A. nilotica, $P$. dulce and $Z$. tetragona the unit-inflorescences develop sylleptically from axillary buds, but there is temporal differentiation of the buds: only those buds formed at the end of the formation of the RGU develop into unit-inflorescences.

Lysiloma microphyllum and Pithecellobium dulce are unusual in that there is simultaneous blooming of unit-inflorescences that have developed both proleptically and sylleptically on axillary buds; the proleptic ones from a previous RGU, the sylleptic ones form a current RGU. Following the definition of inflorescence presented by Grimes (1992) the inflorescence of these species is not the totality of unit-inflorescences produced along a stem made up of many RGUs, but rather the series of one or few floriferous nodes of the short-shoots.

\section{Acknowledgements}

This research was supported by the Harding Laboratory of the New York Botanical Garden. The generosity of the Director, Dr. D.W. Stevenson is gratefully acknowledged. I wish to thank the following staff of the Propagation Range of the New York Botanical Garden for access to the collections, and for adopting some of my orphaned specimens: Len Marino, Mobee Weinstein, Greg Pietrowski, Francisca Coelho, Sharita Mason and James Harkins.

\section{References}

Briggs, B.G. \& Johnson, L.A.S. (1979) Evolution in the Myrtaceae - Evidence from inflorescence structure. Proc, Linn. Soc. New South Wales 102: 157-256.

Brown, C.L. \& Sommer, H.E. (1992) Shoot growth and histogenesis of trees possessing diverse patterns of shoot development. Amer. J. Bot. 79: 335-346. 
Coen, E.S. (1991) The role of homoeotic genes in flower development and evolution. Ann. Rev. Plant Physiol. Plant Mol. Bio. 42: 241-279.

Cremer, K.W. (1972) Morphology and development of the primary and accessory buds of Eucalyptus regnans. Aust. J. Bot. 20: 175-195.

De Queiroz, K. (1985) The ontogenetic method for determining character polarity and its relevance to phylogenetic systematics. Syst. Zool. 34: 280-299.

Dickison, T.A. (1978) Epiphylly in angiosperms. Bot. Rev. (Lancaster) 44: 181-232.

Dickison, T.A. \& Sattler, R. (1974) Development of the epiphyllous inflorescence of Phyllonoma integerrima (Turcz.) Loes.: implications for comparative morphology. Bot. J. Linn, Soc. 69: 1-14.

Dormer, K.J. (1954) Observations on the symmetry of the shoot of Vicia faba and some allied species, and on the transmission of some morphogenetic impulses. Ann. Bot., n.s. 18: 55-70.

Gould, S.J. (1977) Ontogeny and phylogeny (Belknap Press: Cambridge, MA).

Grimes, J. (1992) Metamerism, heterochrony, and inflorescence morphology, with special reference to the Pithecellobium-complex (Leguminosae: Mimosoideae: Ingeae). Brittonia 44: 140-159.

Grimes, J. (1995) Generic relationships of Mimosoideae tribe Ingeae, with emphasis on the New World Pithecellobium-complex. Pp. 101-121 in Crisp, M. \& Doyle, J.J. (eds.), Advances in Legume Systematics 7: Phylogeny (Royal Botanic Gardens: Kew).

Hallé, F., Oldeman, R.A.A \& Tomlinson, P.B. (1978) Tropical trees and forests: an architectural analysis (Springer-Verlag: Berlin).

Hill, J.P. \& Lord, E.M. (1989) Floral development in Arabidopsis thaliana : a comparison of the wild type and the homeotic pistillata mutant. Canad. J. Bot. 67: 2922-2936.

Lehman, N.L. \& Sattler, R. 1993. Homeosis in floral development of Sanguinaria canadensis and S. canadensis 'Multiplex' (Papaveraceae). Amer. J. Bot. 80: 1323-1335.

Lord, E.M. (1991) The concepts of heterochrony and homeosis in the study of flora morphogenesis. Flowering Newsletter 11: 4-13.

Lyndon, R.F. (1994) Control of organogenesis at the shoot apex. New Phytol. 128: 1-18.

Martinez, S. (1975) Estudio morfológico de las yemas axilares de algunas Leguminosas leñosas de la flora argentina. Darwiniana 19: 458-489.

Mauseth, J.D. (1988) Plant Anatomy (Benjamin/Cummings: Menlo Park, California).

Romberger, J.A. (1963) Meristems, growth, and development in woody plants. U.S.D.A. Forest Service Tech. Bull. 1293.

Sattler, R. (1975a) The development of the epiphyllous inflorescence of Helwingia japonica. Amer. J. Bot. 62: 963-973.

Sattler, R. (1975b) Organvershiebungen und Heterotopien bei Blütenpflanzen. Bot. Jahrb. Syst. 95 : 256-266.

Sattler, R. (1988) Homeosis in plants. Amer. J. Bot. 75: 1606-1617.

Sattler, R. \& Maier, U. (1977) Development of the epiphyllous appendages of Begonia hispida var. cucullifera. Implications for comparative morphology. Can. J. Bot. 55: 411-425.

Stein, O. (1975) The shoot of Hymenaea courbaril (Leguminosae). Amer. J. Bot. 62: 303-310.

Tomlinson, P.B. (1978) Branching and axis differentiation in tropical trees. Pp. 187-207 in Tomlinson, P.B. \& Zimmerman, M.H. (eds.), Tropical Trees as Living Systems (Cambridge University Press: Cambridge).

Tomlinson, P.B. \& Gill, A.M. (1973) Growth habits of tropical trees: some guiding principles. Pp. 129-143 in Meggers, B.J., Ayensu, E.S. \& Duckworth, W.D (eds.), Tropical Forest Ecosystems in Africa and South America: a Comparative Review (Smithsonian Institution Press: Washington, DC).

Tourn, G.M., Tortosa, R.D. \& Medan, D. (1992) Rhamnaceae with multiple lateral buds: an architectural analysis. Bot. J. Linn. Soc. 108: 275-286.

Tucker, S.C. (1963) Development and phyllotaxis of the vegetative axillary bud of Michelia fuscata. Amer. J. Bot. 50: 661-668. 